\title{
Structural and microhardness changes during long-term storage of Ti-Ni shape memory alloys after plastic deformation
}

\author{
A.V. Korotitskiy ${ }^{\text {a }}$, K.E. Inaekyan ${ }^{1}$, V. Brailovski ${ }^{1}$, S.D. Prokoshkin \\ Moscow Institute of Steel and Alloys, 4, Leninsky prosp., Moscow 119049, Russia \\ ${ }^{1}$ Ecole de Technologie Superieure, 1100, Notre-Dame Street West, Montreal, H3C 1K3, Canada
}

\begin{abstract}
Quenched Ti-50.26at.\%Ni and Ti-50.6at.\%Ni shape memory alloys samples were subjected to cold rolling $(\mathrm{CR})$ with true strains from moderate (logarithmic thickness reduction $e=0.25)$ to severe $(e=$ 2.1). The evaluation of structural changes in the material during its long-term storage was performed using Vickers microhardness (HV), Differential Scanning Calorimetry (DSC) and X-ray diffraction techniques. It was shown that during storage, microhardness varied following a dome-shaped trend, thus reflecting the commonly encountered interaction between two concurrent time-dependent phenomena, the first responsible for material post-deformation hardening, and the second, for material post-deformation softening.
\end{abstract}

\section{Introduction}

Severe plastic deformation produces ultrafine grained and amorphous structures in Ti-Ni shape memory alloys (SMA) [1-4]. These structures are strongly non-equilibrium and could undergo evolution even at room temperature. Two main phenomena can explain this structural instability: isothermal austenite to martensite phase transformation [5] and amorphous to nanocrystalline structural transformation [3]. The first transformation was not observed in the coarse-grained Ti-Ni alloys [6], while it was reported for the nanocrystalline alloys [5]. As the structural stability of an alloy determines its functional stability, it is important to examine the evolution of such a general mechanical characteristic of metallic alloys as microhardness during a long-term postdeformation storage of deformed Ti-Ni SMA.

It was shown in [7] that, during a long-term storage, microhardness of the deformed Ti-50.26at.\%Ni alloy varied following a dome-shaped trend, thus reflecting the commonly encountered interaction between the two concurrent time-dependent phenomena, the first responsible for material hardening, and the second, for material softening. For such a phenomenon, a simple mathematical model was proposed and experimentally validated [7]: at room temperature (RT), the microhardness value depends on the cold-work strain $(e)$ and time $(t)$ as:

where:

$$
H V(e, t)=H V_{0}+K_{1} \exp \left(-\alpha_{1} \cdot t\right)+K_{2}\left[1-\exp \left(-\alpha_{2} \cdot t\right)\right]
$$

$$
\begin{array}{ll}
K_{1}=f(e)=\lim _{t \rightarrow 0} \Delta H V_{1} & - \text { strain-induced hardening (immediately after cold work), followed by post- } \\
& \text { deformation softening; } \\
K_{2}=f(e)=\lim _{t \rightarrow \infty} \Delta H V_{2} & \begin{array}{l}
\text { - hypothetic limit of hardening caused by post-deformation ageing-related } \\
\text { phenomena; }
\end{array} \\
\tau_{1}=1 / \alpha_{1} \text { and } \tau_{2}=1 / \alpha_{2} & \begin{array}{l}
\text { - characteristic times of the softening and hardening phenomena related to } \\
\text { room temperature storage. }
\end{array}
\end{array}
$$

In this work, the developed model of the microhardness evolution was extended to the entire family of binary Ti-Ni SMA by studying microhardness and structure changes of the cold-worked Ti-50.26 and Ti50.6 at.\%Ni shape memory alloys during their isothermal storage at room and elevated (up to $300^{\circ} \mathrm{C}$ ) temperatures.

\footnotetext{
a e-mail: akorotitskiy@rambler.ru
} 


\section{Experiments}

Ti-50.26 and Ti-50.6at.\%Ni $\varnothing \approx 1 \mathrm{~mm}$ wire samples were solution-treated at $700^{\circ} \mathrm{C}(30 \mathrm{~min})$, water-cooled and then subjected to cold rolling (CR). The true CR strain varied from $e=0.25$ to $2.1 ; e=\ln \left(h_{0} / h_{i}\right)$, where $h_{0}$ and $h_{i}$ - are the sample thickness before and after processing.

The Vickers microhardness was measured using an INSTRON 2100 Wilson-Tukon testing machine $(500 \mathrm{~g}$ load) immediately after cold work and in the course of the long-term post-deformation storage.

The X-ray diffractograms were obtained in $C u_{K \alpha}$ radiation using a "PANalytical X'pert-Pro" diffractometer.

The crystallization and grain growth heat effects were measured using a Perkin-Elmer Pyris 1 DSC (Differential Scanning Calorimeter) with a heating rate of $50^{\circ} \mathrm{C} / \mathrm{min}$.

\section{Results and Discussion}

\subsection{Effects related to cold-work}

The X-ray diffraction study showed that an increase in cold-rolling strain results in a martensite texture development, in an increase in the B2-austenite fraction and in a general X-ray line widening due to dislocation density growth, grain refinement and amorphization (Fig.1).

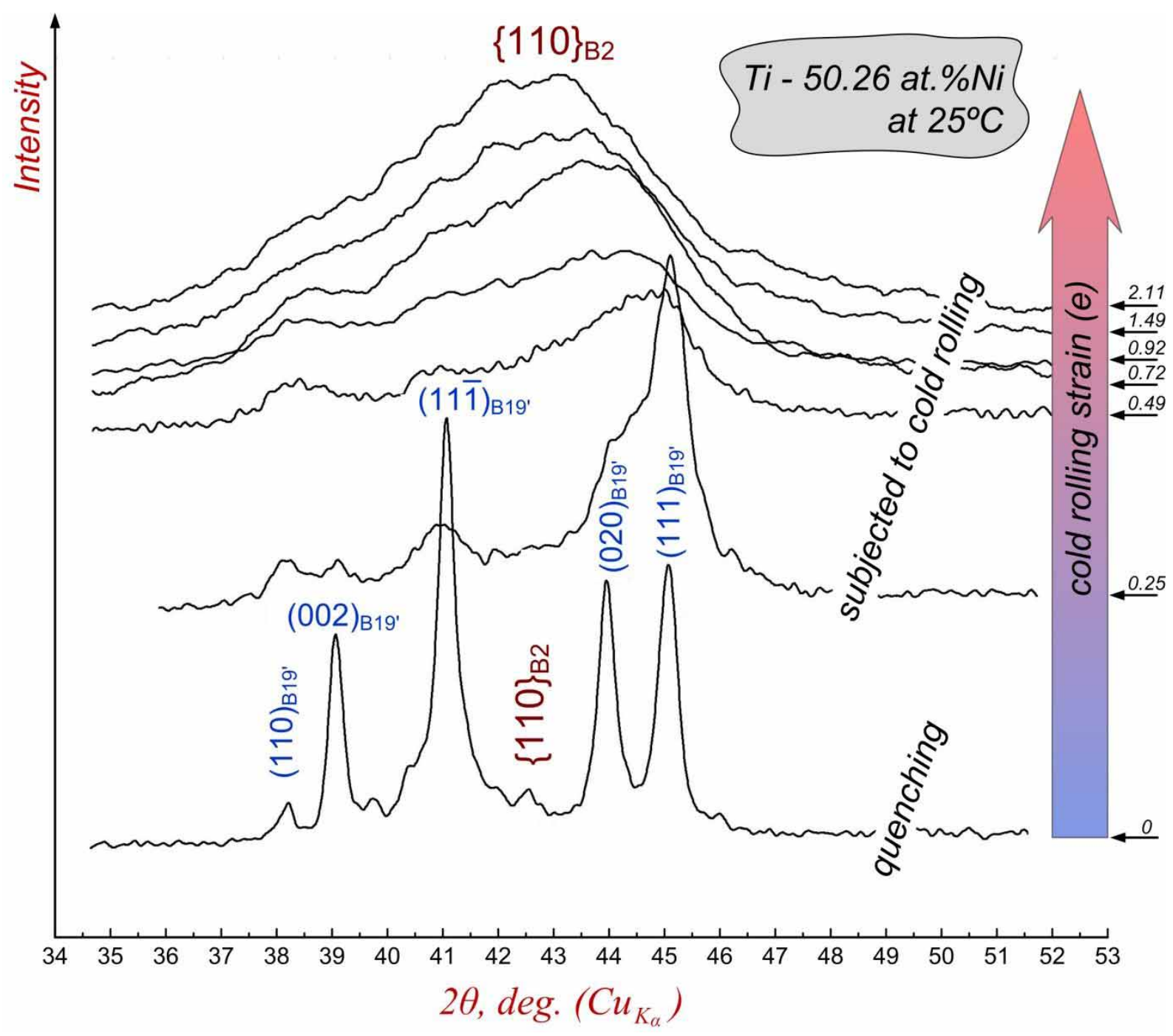

Fig. 1. Comparison of the X-ray line profiles of Ti-50.26at.\%Ni alloy deformed to various strains (B2-austenite, B19'martensite). 
DSC study showed (Fig.2), that an increase in plastic deformation intensity results in an increase in the temperature and the temperature range of the reverse martensitic transformation combined with a decrease in the endothermic heat effect related to this transformation. This is due to the martensite stabilization and the corresponding decrease in the martensite quantity with an increase in CR strain [5]. When the CR strain is higher than $e=1$, the heat effect of the reverse martensitic transformation is not distinctly detected (Fig.2) despite some martensite still presents (see Fig.1).

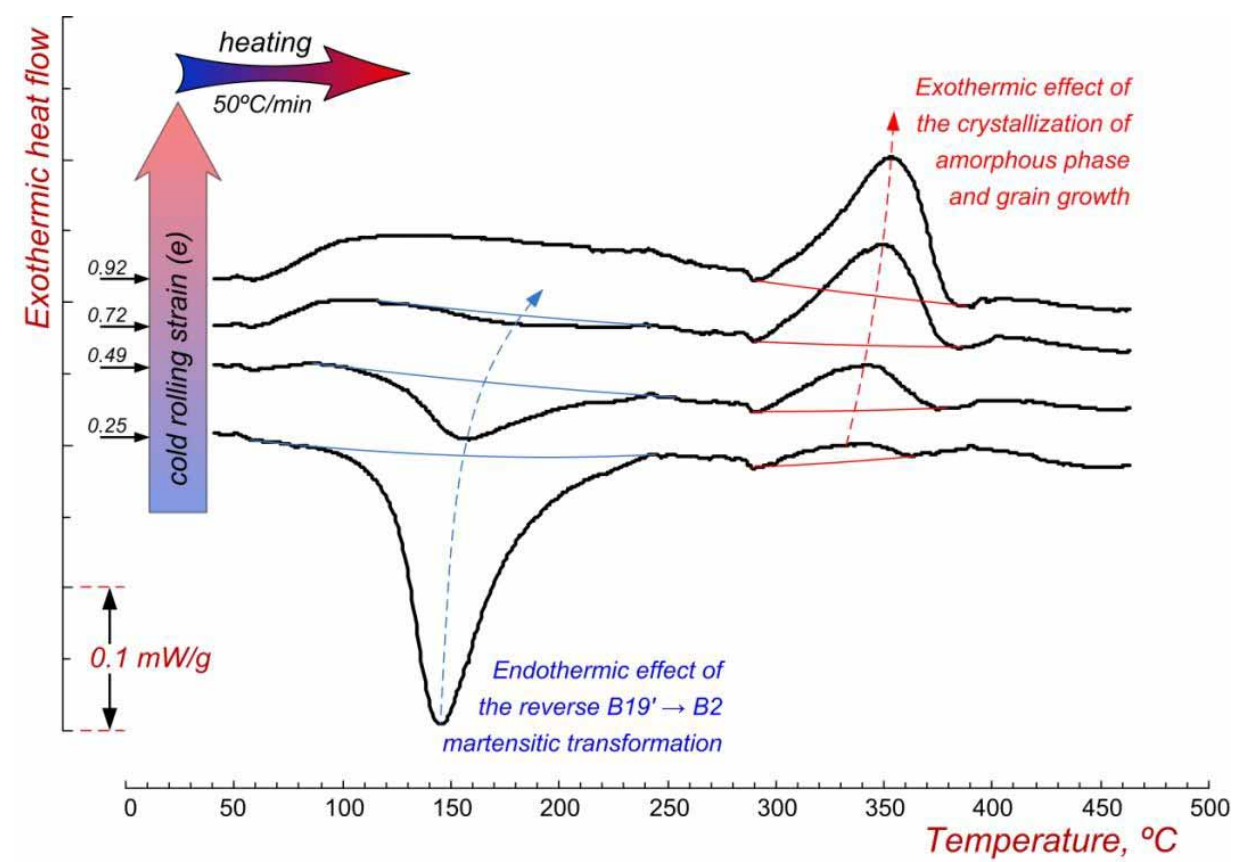

Fig. 2. DSC heating curves of Ti-50.26at.\%Ni alloy after cold rolling with $e=0.25,0.49,0.72$ and 0.92 .

The severely deformed $\mathrm{Ti}-\mathrm{Ni}$ samples produce an exothermic effect which corresponds to the crystallization of amorphous phase and nanograin growth [8]. An increase in the crystallization enthalpy and a shift of the peak position to higher temperatures (see Fig.2) reflects an increase in the thermal stability and volume fraction of amorphous phase with an increase in CR strain (see Fig.3). According to Buschow [9], the reference value of the crystallization heat flow for $100 \%$ amorphous $\mathrm{Ti}-\mathrm{Ni}$ alloy obtained by melt spinning is $3.5 \mathrm{~kJ} / \mathrm{mol}$ (under DSC heating rate of $50^{\circ} \mathrm{C} / \mathrm{min}$ ). Based on this reference value, an amorphous phase fraction could be calculated. For example, the plastic deformation up to 2 seems to be capable of forming about $\approx 30 \%$ of the amorphous phase fraction in Ti-50.26\%Ni alloy (see Fig.3). However, as shown in [8], this exothermic effect in cold-rolled Ti-Ni alloys comprises in fact two effects (one from crystallization of the amorphous phase and second from the nanograin growth) which could not be separated. Therefore, one cannot rely upon DSC to evaluate the exact quantity of the amorphous phase.

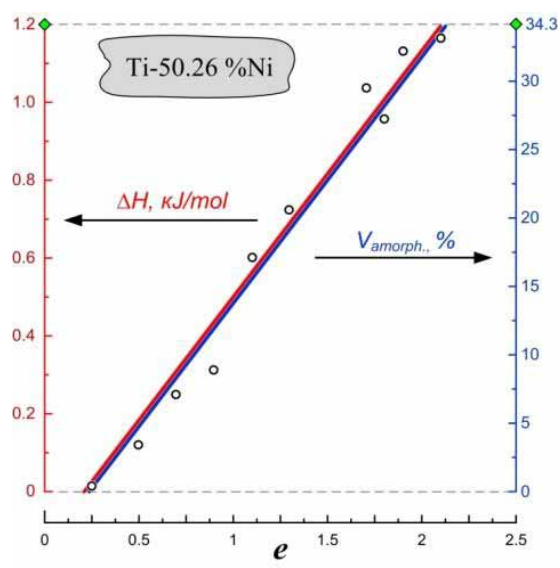

Fig. 3. Strain dependencies of the crystallization heat flow and hypothetic volume fraction of amorphous phase. 
Cold work of the binary Ti-Ni shape memory alloys with strains up to $e=2.1$ forms different kinds of structures: dislocation-hardened substructure, nanocrystalline and amorphous structures sequentially [4]. The effect of the cold work intensity on microhardness of the binary Ti-Ni SMA is shown in Fig.4.

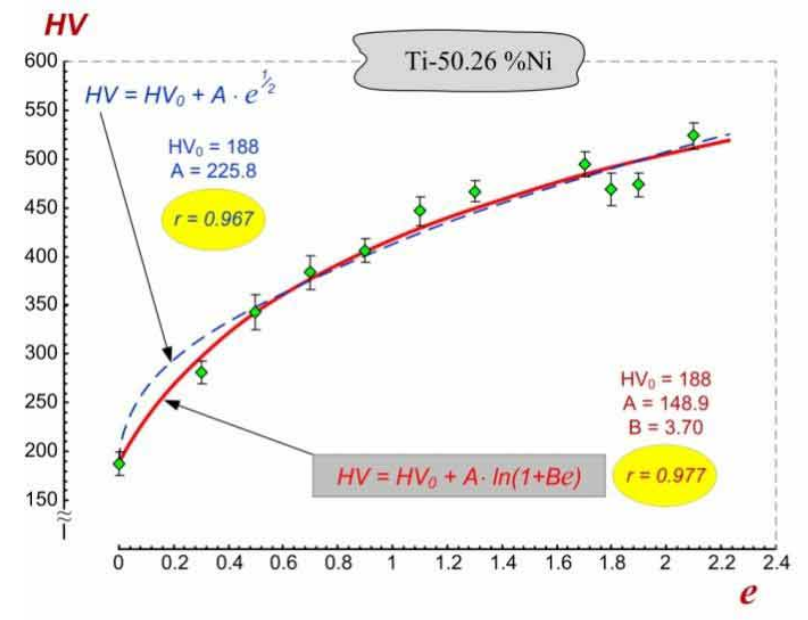

a)

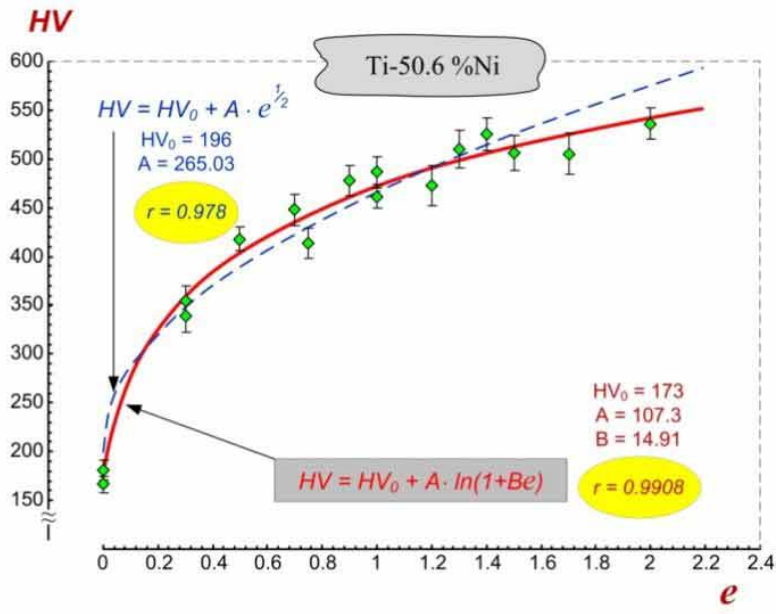

b)

Fig. 4. Vickers microhardness as a function of cold work strain (e): experimental and approximated data:

(a) Ti-50.26at.\%Ni [7] and (b) Ti-50.6at.\%Ni (this work).

The following hardening trend can be formulated [7]: strain-induced hardening at a given moment of deformation is inversely proportional to the total amount of strain accumulated up to that moment:

$$
d(H V)=\frac{1}{a e+b} d e
$$

where $a$ and $b$ are the numerical coefficients.

After integration, we obtain a monotonous increase in HV with an increase in cold-work strain which can be expressed by the following logarithmic law:

$$
H V(e)=H V_{0}+A \cdot \ln (1+B e)
$$

where: $H V_{0}$ is the microhardness of the quenched (non-deformed) alloy; and $A, B$ are the numerical coefficients.

\subsection{Microhardness as a function of cold work strain and storage time}

HV as a function of storage time (plotted for both alloys in Fig.5 after selected cold work strains) forms a domeshaped curve, which reflects an interaction between two concurrent time-dependent phenomena: the first responsible for post-deformation hardening $\left(\Delta H V_{2}\right)$ - ageing-related phenomena, and the second, responsible for post-deformation softening $\left(\Delta H V_{l}\right)$ - related to all energy releasing (recovery) processes that do not require the movement of high-angle boundaries, such as dislocation rearrangement, point-defects concentration decrease and stress relaxation.

By considering concurrent hardening/softening trends, the following expression for the microhardness can be proposed [7]:

$$
H V=H V_{0}+\Delta H V_{1}+\Delta H V_{2}
$$


Generally, $\Delta H V_{l}$ and $\Delta H V_{2}$ depend on the cold work strain (e), time ( $t$ ) and temperature (T). However, at a constant temperature, which is a near room temperature, they are functions of " $e$ " and " $t$ " only:

or, in detail:

$$
H V(e, t)=H V_{0}(\text { const })+\Delta H V_{1}(e, t)+\Delta H V_{2}(e, t)
$$

$$
H V(e, t)=H V_{0}(\text { const })+A_{1} \cdot \ln \left(1+B_{1} \cdot e\right) \cdot \exp \left(-\alpha_{1} \cdot t\right)+A_{2} \cdot \ln \left(1+B_{2} \cdot e\right) \cdot\left[1-\exp \left(-\alpha_{2} \cdot t\right)\right]
$$

where:

$$
\tau_{1}=1 / \alpha_{1}=C_{I}+D_{I} \cdot\left[\exp \left(K_{I} \cdot e\right)-1\right]+E \cdot[\exp (F \cdot e)-1]
$$

- the characteristic times of the softening process duration;

$$
\tau_{2}=1 / \alpha_{2}=C_{2}+D_{2} \cdot \exp \left(K_{2} \cdot e\right)
$$

- the characteristic times of the hardening process duration; and $A, B, C, D, E, F, K$ - the numerical coefficients.

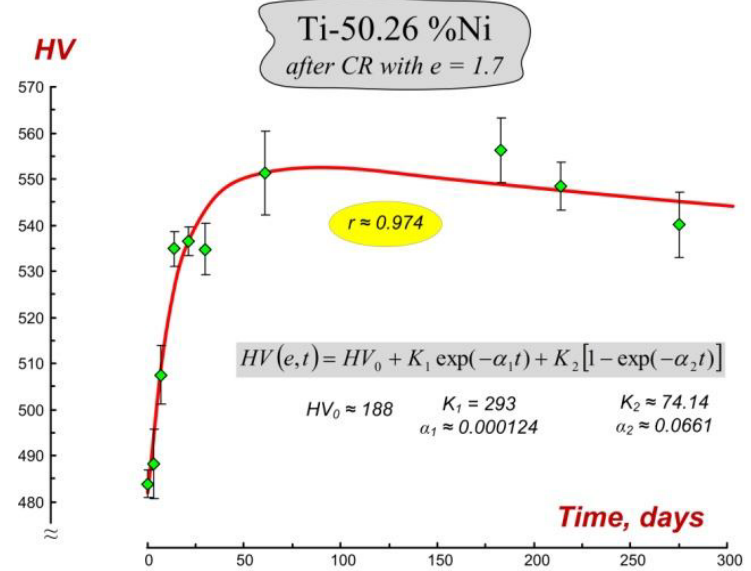

a)

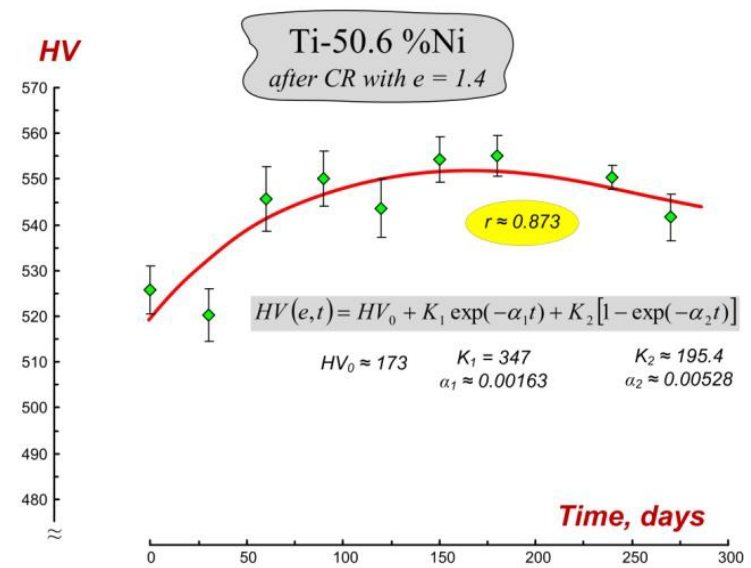

b)

Fig. 5. Comparison between modeled and experimental data related to the microhardness evolution during storage at RT: (a) Ti-50.26at.\%Ni after cold-rolling with $e=1.7$, (b) Ti-50.6at.\%Ni after cold-rolling with $e=1.4$.

\subsection{Microhardness as a function of post-deformation storage temperature and duration}

Microhardness of the severely deformed $(e=1.72)$ Ti-50.26at.\%Ni samples during their storage at a constant temperature encompassing between RT and $300^{\circ} \mathrm{C}$ follows a common trend (Fig.6): an increase up to a certain maximum followed by a decrease. However, time to reach the HV maximum significantly decreases as the annealing temperature increases (see Fig.6). It can be reasonably supposed that in the temperature range from RT to $300^{\circ} \mathrm{C}$, the observed changes in microhardness are caused by the same structural phenomena.

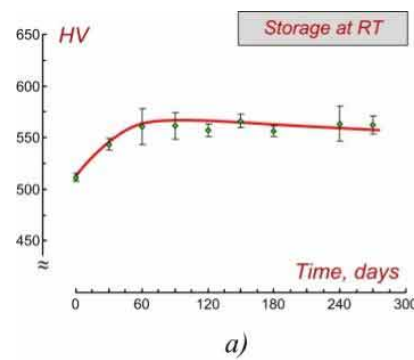

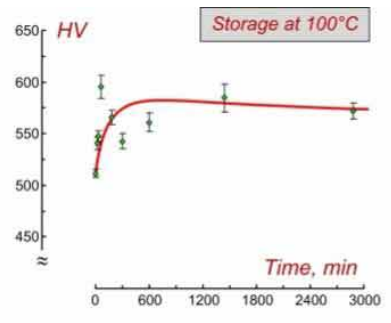

b)

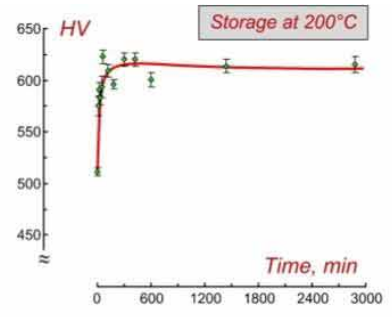

c)

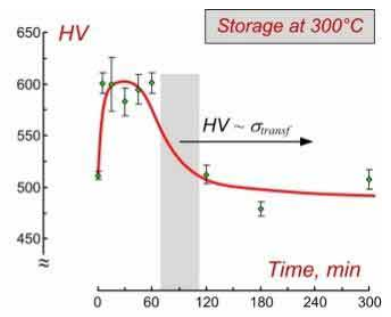

d)

Fig. 6. Microhardness changes during isothermal storage (annealing) of Ti-50.26\%Ni alloy at (a) RT, $(b) 100^{\circ} \mathrm{C},(c) 200^{\circ} \mathrm{C}$, (d) $300^{\circ} \mathrm{C}$ after $\mathrm{CR}, e=1.72$. 
Comparison of the HV-time dependence for the RT-storage up to 270 days and annealing at 100 and $200^{\circ} \mathrm{C}$ up to 48 hours and annealing at $300^{\circ} \mathrm{C}$ up to 5 hours (Fig.6) shows that the highest $\mathrm{HV}$ is reached after annealing at about $200^{\circ} \mathrm{C}(5-10 \mathrm{hrs})$. After post-deformation annealing at 100 and $200^{\circ} \mathrm{C}$ up to $48 \mathrm{hours}$, $\mathrm{HV}$ increases and remains higher than that after RT-storage up to 9 months. After annealing at $300^{\circ} \mathrm{C}, 1.5 \mathrm{hrs}, \mathrm{HV}$ decreases sharply because of the martensitic transformation induced by indentation (see Fig.6d). The presence of the martensitic transformation after annealing at $300^{\circ} \mathrm{C}(1.5-5 \mathrm{hrs})$ is confirmed by the decrease in the crystallization and grain-growth exothermic heat flow (see Fig.7c) and by the appearance of the weak endothermic peak at a temperature of approximately $50^{\circ} \mathrm{C}$.

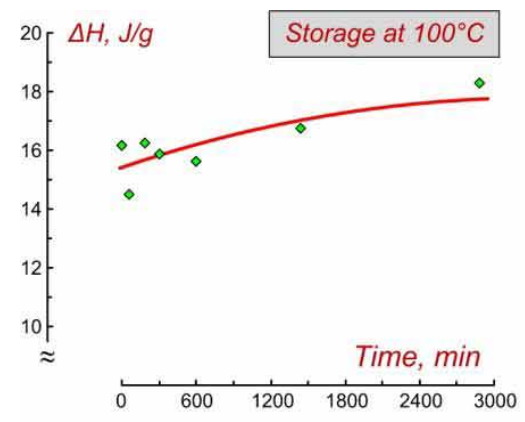

a)

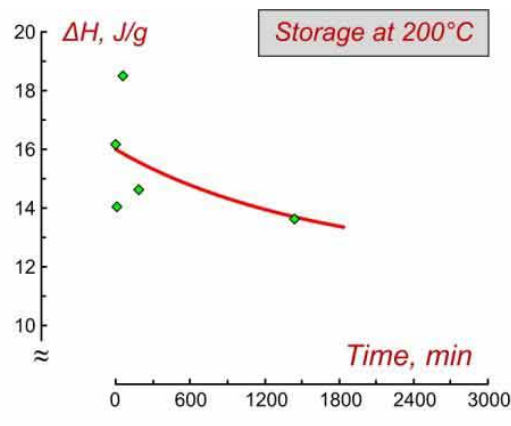

b)

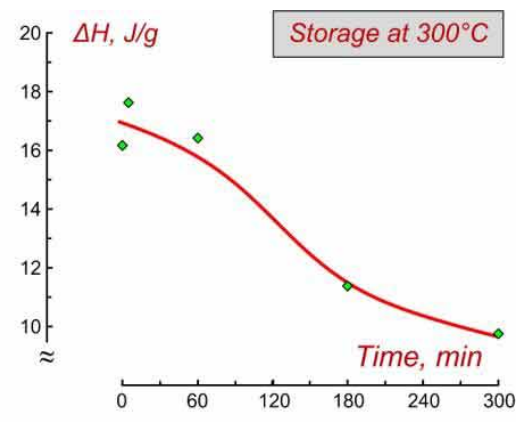

c)

Fig. 7. Crystallization and grain-growth heat flow for Ti-50.26\% Ni alloy after $\mathrm{CR}, e=1.72+$ storage at $100^{\circ} \mathrm{C}(a), 200^{\circ} \mathrm{C}$ (b) and $300^{\circ} \mathrm{C}(c)$

An interesting observation should be made: (1) heat flows due to crystallization and grain-growth after annealing at $325^{\circ} \mathrm{C}(10 \mathrm{~min})[10]$ and $300^{\circ} \mathrm{C}(3 \mathrm{hrs})$ of the $\mathrm{CR}$ Ti-50.26\% Ni alloy $(e=1.72)$ are similar $(\approx 11 \mathrm{~J} / \mathrm{g})$; $(2)$ a weak endothermic effect is observed around $50^{\circ} \mathrm{C}$ in both cases. Thus, the temperature-time equivalence can tentatively be expressed as $325^{\circ} \mathrm{C}(10 \mathrm{~min}) \approx 300^{\circ} \mathrm{C}(3 \mathrm{hrs})$. However, the microhardness of the sample annealed at $325^{\circ} \mathrm{C}(10 \mathrm{~min})$ is significantly higher than of those annealed at $300^{\circ} \mathrm{C}(3 \mathrm{hrs}): 587 \pm 9 \mathrm{MPa}$ towards $479 \pm 7 \mathrm{MPa}$.

\section{Conclusions}

1. For binary Ti-Ni SMA, microhardness as a function of the CR strain varying from moderate to severe can be expressed as: $H V(e)=H V_{0}+A \cdot \ln (1+B e)$, where $H V(e) \approx 188+148.9 \cdot \ln (1+3.7 \cdot e)$ for Ti50.26 at. $\% \mathrm{Ni}$ and $H V(e) \approx 173+107.3 \cdot \ln (1+14.91 \cdot e)$ for Ti-50.6at.\%Ni alloys.

2. The microhardness evolution trends observed during RT-storage of the severely deformed Ti-50.26 and Ti50.6 at.\%Ni alloys are similarly dome-shaped. The maximum microhardness of Ti-50.6at.\%Ni alloy is reached after a storage, which is from two to three times longer than of Ti-50.26at.\%Ni alloy.

3. The shape of $\mathrm{HV}(\mathrm{t})$ curve for Ti-50.26at.\%Ni alloy during the initial stage of storage is the same in the RT $\div 300^{\circ} \mathrm{C}$ range: they are dome-shaped, and the time needed to reach the $\mathrm{HV}$ maximum significantly decreases with an increase in annealing temperature. Thus, the main structure mechanisms of the hardening/softening processes are the same.

This work has been carried out with the financial support of the Natural Science and Engineering Research Council of Canada (Fonds de recherche sur la nature and les technologies du Québec, FQRNT) and the Ministry for Education and Science of the Russian Federation. 


\section{References}

[1] V.B. Fedorov, V.G. Kurdiumov, D.K. Khakimova et al., Doklady Academii Nauk SSSR, 269, 885 (1983)

[2] D. Koike, M. Parkin and M. Nastasi, J. Mater.Res. 5, 1414 (1990)

[3] A.V. Sergueeva, C. Song, R.Z. Valiev and A.J. Mukherjee, Mater. Sci. Eng. A 339, 159 (2003)

[4] V. Brailovski, S.D. Prokoshkin, I.Y. Khmelevskaya et al., Mater. Trans.JIM 47, 795 (2006)

[5] S.D. Prokoshkin, I.Y. Khmelevskaya, S.V. Dobatkin et al, Acta materialia 53 (2005), 2703-2714

[6] K. Otsuka, X. Ren, T. Takeda, Scripta Mater. 45, 145 (2001)

[7] A.V. Korotitskiy, K.E. Inaekyan, V. Brailovski, S.D. Prokoshkin, Materials Science Forum, Nanomaterials by Severe Plastic Deformation IV, 584-586, 1039 (2008).

[8] K. Inaekyan, V. Brailovski, S. Prokoshkin, A. Korotitskiy, A. Glezer, Journal of Alloys and Compounds, 473, 71 (2009).

[9] K.H.K. Buschow, "Stability and electrical transport properties of amorphous $\mathrm{Ti}_{1}-\mathrm{X}-\mathrm{Ni}_{\mathrm{x}}$ alloys", J. Phys. F: Met. Phys. 13, 563 (1983)

[10] V. Brailovski, K.E. Inaekyan, S.D. Prokoshkin, A.V. Korotitskiy, A. Glezer, "Structure and properties features of nanostructured Ti-Ni SMA after severe plastic deformation and post-deformation annealing", Proc.Int.Conf. SMST'2007, Tsukuba (Japan), 03-05.12.2007, edited by S. Miyazaki (ASM International, Materials Park, DH, 2008), p. 17 